\title{
The value of context
}

Published at www.cmaj.ca on Oct. 29

I sat in the waiting room of the government hospital in the town of Puliangudi in the southern India state of Tamil Nadu. In my Canadianaccented Tamil, I had sought permission to speak to my supervisor inside the operating theatre.

I clearly needed to brush up on my grammar: The nurses shrugged, smiled and directed me to sit on a wooden bench.

The other visitors and I watched as women were carried out of the theatre every 10 minutes, legs and shoulders supported by attending nurses. They were laid on the floor before us, some moaning, others peaceful. Typically, they quickly adjusted their brilliantly coloured saris to hide their ankles.

Everyone looked on with large eyes. It is not customary to hide curiosity in India. Such is life.

Eventually, I gained entrance to the operating room. Doctors and nurses worked at two stations, scraping out the uteruses of women undergoing dilation and curretage procedures (D\&Cs) for abortion. The medical professionals I spoke to in the village were supportive: use of the procedure helps control overpopulation, and birth control awareness is lacking. In India, many women want to cap their family size after having two children. Each time they become pregnant again, they come in for a D\&C. Because many people, especially in smaller villages and towns, do not believe in using condoms or do not have access to them, a D\&C serves as their method of birth control.

The women often whimpered or cried in pain. But no one paid attention. In the cases I saw, none of their

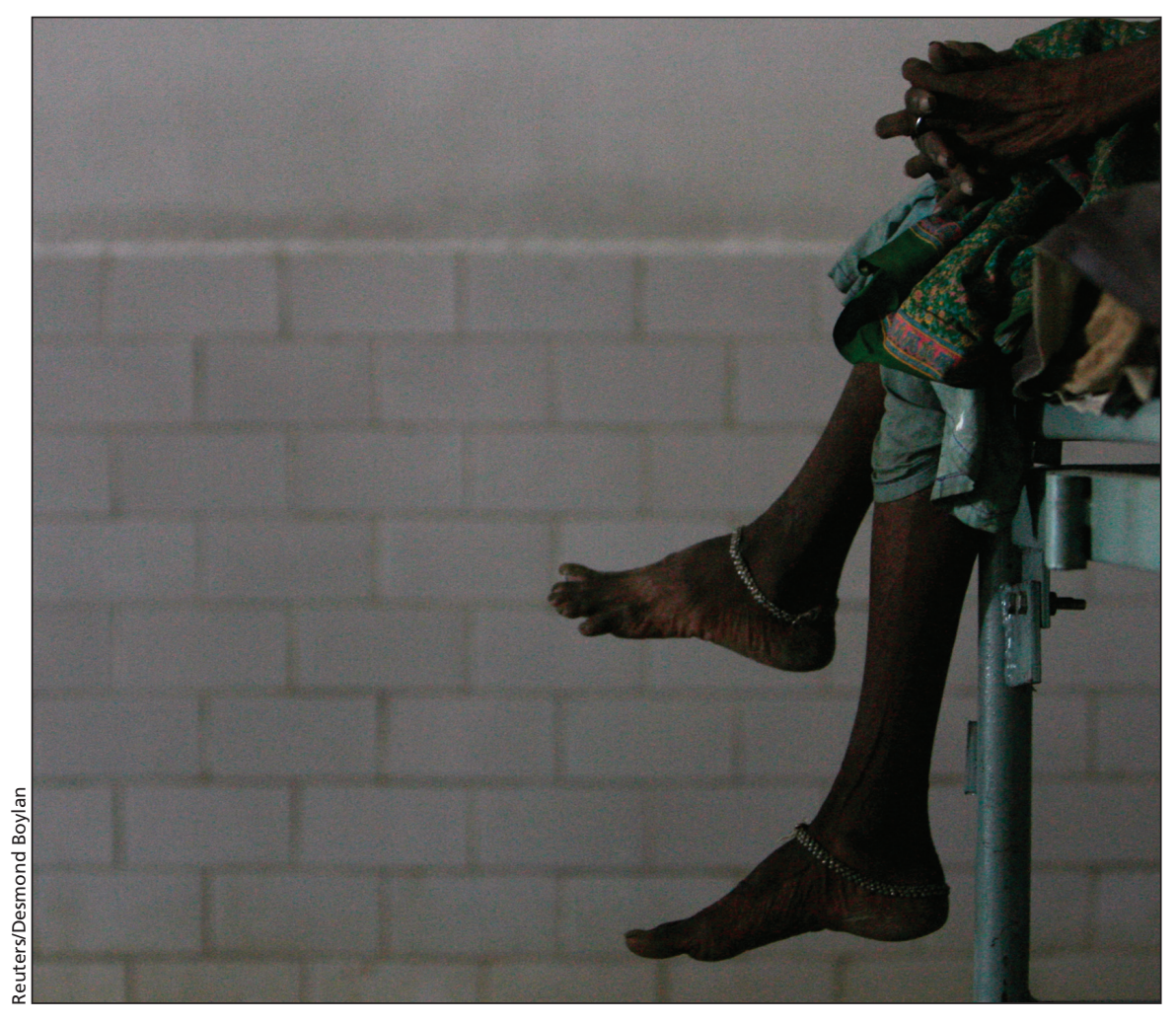

A tribal patient sits on a bed in a ward of a local hospital in India.

family members were in the room, and none were waiting outside. I could not help but feel sad for these women, all alone.

At first, I was shocked that they were not given a general anesthetic. One woman was injected with diazepam about halfway through the procedure.

Then I caught myself.

As a young student, I learned not to compare, but rather to appreciate. These hospitals serve people who cannot afford the fee of upwards of 7000 rupees (about \$160) charged for an abortion with general anesthesia in a private clinic. Nurses at a local private hospital had warned me about the unsanitary conditions of the government hospitals - the reuse of gloves and needles. But as the patients and I looked on, we saw instead the skill and patience of the doctors.

It is important to appreciate in context - the culture, the customs. This is life in Puliangudi. And it works. - Abi Vijenthira, Hamilton, Ont.

DOI:10.1503/cmaj.109-3093

CMAJ invites contributions to "Dispatch from the medical front," in which physicians and other health care providers offer eyewitness glimpses of medical frontiers, whether defined by location or intervention. Submissions, which must run a maximum 700 words, should be forwarded to: wayne.kondro@cmaj.ca 